\title{
Comparison of susceptibility of Neisseria meningitidis to sodium sulphadiazine and sodium fusidate in
}

\section{vitro}

\author{
R. S. MILES AND A. MOYES \\ From the Department of Bacteriology, University of Edinburgh Medical School, Edinburgh, UK
}

SUMMARY Out of 100 strains of meningococci examined 62 were resistant to $1 \mathrm{mg} / 1$ or more of sodium sulphadiazine, including $82 \%$ of group W135 strains and $69 \%$ of group B strains. All strains were sensitive in vitro to $0.5 \mathrm{mg} / 1$ of sodium fusidate. Sodium fusidate should be considered as a chemoprophylactic agent for those who may be at risk of meningococcal disease.

When prevalence of meningococcal disease is increased contacts of cases may require chemoprophylaxis, and sodium sulphadiazine is the drug of choice. However, increasing numbers of meningococci are resistant to sulphonamides (Fallon, 1975, 1977) and many alternative chemoprophylactic agents are ineffectual. Sodium fusidate is active against a few strains of meningococci in vitro (Barber and Waterworth, 1962; Godtfredsen et al., 1962). We report an in-vitro study of the susceptibility of 100 strains of Neisseria meningitidis to sodium fusidate and sodium sulphadiazine.

\section{Material and methods}

\section{STRAINS OF MENINGOCOCCI}

One hundred strains of meningococci were examined. Eighty-seven of them had been isolated from throat swabs of patients attending the Department for Sexually Transmitted Diseases, The Royal Infirmary of Edinburgh; one had been isolated from the cerebrospinal fluid of a young male patient; and 12 were from laboratory stock cultures. All strains from patients were isolated on Columbia agar base enriched with $10 \%$ heated human blood. $80 \%$ of the concentrations of vancomycin, colistin, and nystatin recommended by Thayer and Martin (1966) were incorporated in the agar. All strains were identified by a rapid carbohydrate utilisation test (Young et al., 1976). All strains were serologically typed by $\mathrm{Dr}$ R. J. Fallon, Meningococcal Reference Laboratory (Scotland), Ruchill Hospital, Glasgow.

SENSITIVITY TESTING

Sensitivity to sulphonamide was tested on Mueller-

Received for publication 17 October 1977
Hinton agar (Oxoid) by the method of Feldman (1967). Sodium sulphadiazine was added to the agar in varying amounts from 0.1 to $100 \mathrm{mg} / \mathrm{l}$. Sensitivity to sodium fusidate (Leo Laboratories Ltd) was tested by a similar method with antibiotic added to the agar in varying amounts from 0.015 to $1 \mathrm{mg} / \mathrm{l}$. All cultures were incubated at $37^{\circ} \mathrm{C}$ in an atmosphere containing $10 \%$ carbon dioxide.

\section{Results}

\section{SEROTYPING}

The serotypes of the strains are shown in Table 1. Group W135 strains were common and group B strains predominated, although a large proportion $(24 \%)$ of strains were non-groupable. One of the group A strains was isolated from cerebrospinal fluid.

\section{SULPHONAMIDE SENSITIVITY}

The results of testing 100 strains are shown in Table 1. Fourteen strains, including seven group W135 and all three group A strains, were resistant to $10 \mathrm{mg} / \mathrm{l}$ or more of sulphadiazine. They were called fully resistant (Feldman, 1967). Forty-eight strains, including 25 group B, six group W135, and four group C were resistant to $1 \mathrm{mg} / \mathrm{l}$ sulphadiazine but were sensitive to $10 \mathrm{mg} / \mathrm{l}$. They were called partially resistant (Feldman, 1967). Thirty-eight strains were fully sensitive to sulphadiazine and were inhibited by 1.0 $\mathrm{mg} / \mathrm{l}$. In all, 62 strains were either partially or fully resistant to sulphadiazine, and this total included 13 $(76 \%)$ of group W135 strains and $27(72 \%)$ of group B strains.

SODIUM FUSIDATE SENSITIVITY

The results of testing 100 strains are shown in 
Table 1 Sensitivity of 100 strains of meningococci to sodium sulphadiazine

\begin{tabular}{|c|c|c|c|c|c|c|c|c|}
\hline \multirow[t]{2}{*}{ Group } & \multicolumn{7}{|c|}{ No. of strains inhibited by sodium sulphadiazine $\left(m g_{l}^{\prime} l\right)$} & \multirow[t]{2}{*}{ Total } \\
\hline & $0 \cdot 1$ & $1 \cdot 0$ & $5 \cdot 0$ & 10 & 50 & 100 & $>100$ & \\
\hline A & & & & & 1 & 1 & 1 & 3 \\
\hline B & & 10 & 15 & 10 & 2 & & & 37 \\
\hline C & & 3 & 1 & 3 & & & 1 & 8 \\
\hline W135 & & 4 & 4 & 2 & 7 & & & 17 \\
\hline $\mathbf{X}$ & & & 1 & & & & & 1 \\
\hline Y & & 4 & 2 & & & & & 6 \\
\hline$Z^{1 / 29 E}$ & & 2 & 2 & & & & & 4 \\
\hline NT & & 15 & 3 & 5 & 1 & & & 24 \\
\hline Total & & 38 & 28 & 20 & 11 & 1 & 2 & 100 \\
\hline
\end{tabular}

NT $=$ not typed.

Table 2 Sensitivity of 100 strains of meningococci to sodium fusidate

\begin{tabular}{|c|c|c|c|c|c|c|c|c|}
\hline \multirow[t]{2}{*}{ Group } & \multicolumn{7}{|c|}{ No. of strains inhibited by sodium fusidate $(\mathrm{mg} / \mathrm{l})$} & \multirow[t]{2}{*}{ Total } \\
\hline & 0.015 & 0.03 & 0.06 & $0 \cdot 12$ & $0 \cdot 25$ & $0 \cdot 5$ & $1 \cdot 0$ & \\
\hline $\mathbf{A}$ & & & & 1 & 2 & & & 3 \\
\hline B & 11 & 15 & 7 & 2 & 1 & 1 & & 37 \\
\hline C & & 4 & 3 & & 1 & & & 8 \\
\hline W135 & 3 & 6 & 6 & 2 & & & & 17 \\
\hline $\mathrm{X}$ & 1 & & & & & & & 1 \\
\hline $\mathbf{Y}$ & & 3 & 3 & & & & & 6 \\
\hline$Z^{1} / 29 E$ & & & 3 & 1 & & & & 4 \\
\hline NT & 4 & 8 & 8 & 3 & & 1 & & 24 \\
\hline Total & 19 & 36 & 30 & 9 & 4 & 2 & & 100 \\
\hline
\end{tabular}

NT =: not typed.

Table 2. Ninety-four strains were inhibited by $0 \cdot 12 \mathrm{mg} / 1$ and all strains were sensitive to $0.5 \mathrm{mg} / \mathrm{l}$ sodium fusidate.

\section{Discussion}

The first known epidemic of meningitis due to sulphonamide-resistant meningococci occurred at a naval training centre in San Diego in 1963 (Millar et $a l ., 1963)$. Since then interest in the clinical aspects of sulphonamide-resistant meningococci has increased. In the United Kingdom the incidence of meningococcal infection increased about threefold between 1967 and 1974 (British Medical Journal, 1976). Although laboratory notifications of isolations of $N$. meningitidis were lower in 1976 than in previous years they remained at a higher level than before 1974 (Fallon, 1977). Fallon (1975) reported an increasing number of strains of meningococci that showed partial resistance to sulphonamides in the laboratory, and many of these strains show more than a marginal partial resistance (Fallon, 1977).

Our results of sulphonamide sensitivity testing were similar to those of Fallon (1977). Eighty-seven of our strains were isolated from persons free from meningococcal disease and $51(58 \%)$ of these organisms were resistant to $1.0 \mathrm{mg} / \mathrm{l}$ of sulphadiazine. A total of 62 strains was resistant to $1.0 \mathrm{mg} / \mathrm{l}$ of sulphadiazine including a high percentage of group W135 and group B strains. This is important because in field prophylaxis trials meningococci resistant to $1.0 \mathrm{mg} / \mathrm{l}$ of sulphadiazine were not eliminated from the nasopharynx by recommended doses of sulphadiazine (Brown and Condit, 1965).

Asymptomatic carriage of $N$. meningitidis is common and between $5 \%$ and $20 \%$ of the general population may harbour the organism in the nasopharynx. In confined populations the carrier rate may rise to over $70 \%$, but an increasing carrier rate does not always mean that meningococcal disease $N$ will occur (Fraser et al., 1973) although during an epidemic of meningococcal disease Kaiser et al. $\bigcirc$ (1974) isolated $N$. meningitidis from pharyngeal $\omega$ cultures of $35 \%$ of close contacts compared with $1 \%$ of controls. In the presence of clinical cases of $c$ meningococcal infection some groups of individuals seem to be at increased risk of disease and may require chemoprophylaxis. These persons include those in the household under 5 years of age together with other close household contacts and infant con- $\stackrel{?}{9}$ tacts in a day nursery. Groups who may also be at $\Phi$ increased risk are military recruits among whose $\overline{2}$ 
ranks meningococcal disease has developed and ship crews who are to spend time at sea and who have been exposed to cases of meningococcal disease. Other individuals, including casual contacts and medical personnel (excluding those who have had intimate contact such as in mouth-tomouth resuscitation), seem to be at little or no increased risk of disease after case contact and do not require chemoprophylaxis (Kaiser et al., 1974).

When the strain of $N$. meningitidis is susceptible to sulphonamides sulphadiazine in full dosage for 24 hours is the best prophylaxis available (Lancet, 1974). When the meningococcus is resistant to sulphonamides many antibacterial agents have been used as prophylactics and have been shown to be ineffective in eliminating meningococci from asymptomatic persons. There is evidence that benzylpenicillin does not work in prophylaxis (Artenstein et al., 1967), although it is essential in treatment, and ampicillin, oxytetracycline, and erythromycin were tried by Dowd et al. (1966) with little success. Rifampicin and minocycline have been recommended for prophylaxis. While rifampicin is moderately effective in eliminating the meningococcal carrier state (Deal and Sanders, 1969; Devine et al., 1970 ) it has caused the rapid selection of rifampicinresistant strains in treated populations (Beam et al., 1971).

Minocycline reduces meningococcal carriage but has the serious disadvantage that it may cause toxic vestibular effects (Williams et al., 1974; Devine et al., 1971), although Masterton and Schofield (1975) claim that when it is given for gonorrhoea the incidence of vestibular side effects is low. Furthermore, minocycline, like other tetracyclines, may cause discoloration of permanent teeth when given to children under 6 years of age and to women in the third trimester of pregnancy (Demers et al., 1968), although this effect may be related to total dose (Grossman et al., 1971). A combination of minocycline and rifampicin eradicates meningococcal carriage but when used sequentially does not prevent the appearance of rifampicin-resistant strains (Devine et al., 1973). Minocycline and rifampicin given at the same time might avoid this problem, but Munford et al. (1974) report a high incidence of unpleasant side effects due to minocycline.

There is as yet no totally acceptable agent suitable for chemoprophylaxis when the strain of $N$. meningitidis is resistant to sulphonamides. In our study 100 strains of meningococci were sensitive in vitro to 0.5 $\mathrm{mg} / \mathrm{l}$ of sodium fusidate. We suggest that this antibiotic, which is well absorbed after oral administration, producing high serum levels with good distribution and penetration (Williamson et al., 1970), and is well tolerated with few side effects, is worthy of clinical trial in those persons who may be at increased risk of meningococcal disease.

We are grateful to the staff of the Bacteriology Department, University of Edinburgh, for providing strains of $N$. meningitidis.

\section{References}

Artenstein, M. S., Lamson, T. H., and Evans, J. R. (1967). Attempted prophylaxis against meningococcal infection using intramuscular penicillin. Military Medicine, 132, 1009-1011.

Barber, M., and Waterworth, P. M. (1962). Antibacterial activity in vitro of fucidin. Lancet, 1, 931-932.

Beam, W. E., Jr, Newberg, N. R., Devine, L. F., Pierce, W. E., and Davies, J. A. (1971). The effect of rifampicin on the nasopharyngeal carriage of Neissera meningitidis in a military population. Journal of Infectious Diseases, 124, 39-46.

British Medical Journal (1976). Meningococcal meningitis in 1975. (News and notes.) British Medical Journal, $1,466$.

Brown, J. W., and Condit, P. K. (1965). Meningococcal infections-Fort Ord and California. California Medicine, 102, 171-180.

Deal, W. B., and Sanders, E. (1969). Efficacy of rifampin in treatment of meningococcal carriers. New England Journal of Medicine, 281, 641-645.

Demers, P., Fraser, D., Goldbloom, R. B., Haworth, J. C., LaRochelle, J., MacLean, R., and Murray, T. K. (1968). Effects of tetracyclines on skeletal growth and definition. Canadian Medical Association Journal, 99, 849-854.

Devine, L. F., and Hagerman, C. R. (1970). Spectra of susceptibility of Neisseria meningitidis to antimicrobial agents in vitro. Applied Microbiology, 19, 329-334.

Devine, L. F., Johnson, D. P., Hagerman, C. R., Pierce, W. E., Rhode, S. L., III, and Peckinpaugh, R. O. (1971). The effect of minocycline on meningococcal nasopharyngeal carrier state in naval personnel. American Journal of Epidemiology, 93, 337-345.

Devine, L. F., Pollard, R. B., Krumpe, P. E., Hoy, E. S., Mammen, R. E., Miller, C. H., and Peckinpaugh, R.O. (1973). Field trial of the efficacy of a previously proposed regimen using minocycline and rifampin sequentially for the elimination of meningococci from healthy carriers. American Journal of Epidemiology, 97, 394-401.

Dowd, J. M., Blink, D., Miller, C. H., Frank, P. F., and Pierce, W. E. (1966). Antibiotic prophylaxis of sulfadiazine-resistant meningococci. Journal of Infectious Diseases, 116, 473-480.

Fallon, R. J. (1975). Meningococcal infections in Scotland, 1974. Communicable Diseases Scotland, 1975, No. 7, pp. v-x.

Fallon, R. J. (1977). Meningococcal infections in Scotland, 1976. Communicable Diseases Scotland, 1977, No. 11, pp. v-x.

Feldman, H. A. (1967). Sulfonamide-resistant meningococci. Annual Review of Medicine, 18, 495-506. 
Fraser, P. K., Bailey, G. K., Abbott, J. D., Gill, J. B., and Walker, D. J. C. (1973). The meningococcal carrierrate. Lancet, 1, 1235-1237.

Godtfredsen, W., Roholt, K., and Tybring, L. (1962). Fucidin, a new orally active antibiotic. Lancet, 1, 928931.

Grossman, E. R., Walchek, A., Freedman, H., and Flanagan, C. (1971). Tetracyclines and permanent teeth: the relation between dose and tooth colour. Paediatrics, 47, 567-570.

Kaiser, A. B., Hennekens, C. H., Saslaw, M. S., Hayes, P. S., and Bennett, J. V. (1974). Seroepidemiology and chemoprophylaxis of disease due to sulfonamideresistant Neisseria meningitidis in a civilian population. Journal of Infectious Diseases, 130, 217-224.

Lancet (1974). Chemoprophylaxis of meningococcal infections. (Leading article.) Lancet, 2, 1431-1432.

Masterton, G., and Schofield, C. B. S. (1975). Vestibular reactions to minocycline. Communicable Diseases Scotland, 1975, No. 38, p. v.

Millar, J. W., Siess, E. E., Feldman, H. A., Silverman, C., and Frank, P. (1963). In vivo and in vitro resistance to sulfadiazine in strains of Neisseria meningitidis. Journal of the American Medical Association, 186, 139-141.

Munford, R. S., Sussuarana de Vasconcelos, Z. J., Phillips, C. J., Gelli, D. S., Gorman, G. W., Risi, J. B., and Feldman, R. A. (1974). Eradication of carriage ofo Neisseria meningitidis in families: a study in Brazil. Journal of Infectious Diseases, 129, 644-649.

Thayer, J. D., and Martin, J. E., Jr. (1966). Improved $\overparen{\Phi}$ medium selective for cultivation of $N$. gonorrhoeae and $\varrho$ N. meningitidis. Public Health Reports (Washington), 81, 559-562.

Williams, D. N., Laughlin, L. W., and Lee, Y-H. (1974). Minocycline: possible vestibular side-effects. Lancet, $2, \bar{c}$ 744-746.

Williamson, J., Russell, F., Doig, W. M., and Paterson, R. W. W. (1970). Estimation of sodium fusidate levels in human serum, aqueous humour and vitreous body. British Journal of Ophthalmology, 54, 126-130.

Young, H., Paterson, I. C., and McDonald, D. R. (1976). W Rapid carbohydrate utilization test for the identification $\mathrm{V}$ of Neisseria gonorrhoeae. British Journal of Venereal? Diseases, 52, 172-175. 